\title{
Product innovation design and its method: From the perspective of embodiment cognition
}

\author{
Shengfang Peng ${ }^{* 1, a}$, Baoying Peng ${ }^{1, \mathrm{~b}}$, Xiaoxuan $\mathrm{Li}^{1, \mathrm{c}}$ \\ ${ }^{1}$ School of Innovation Design Guangzhou Academy of Fine Arts Guangzhou, China
}

\begin{abstract}
In recent years, embodied cognition has become a new approach in the field of cognitive psychology. The shift in cognitive psychology from a focus on the brain to a focus on the human body, just as from the disembodied cognition to the embodied cognition is valuable for many fields related to cognitive science including product design and its method. With Gibson's theory of affordances, embodied cognition is a perfect explanation of today's products guided by the idea of intuitive design and its logic. On the premise of embodied cognition, it is the "Mind-Body complex" that serves as the subject of behavior and interaction, the basis of "natural interaction" in Intelligent age, and the foundation for building a more complete theory of "user experience". Based on the embodied cognitive, the method of design and its research should put more emphasis on specific tools.
\end{abstract}

\section{From the Disembodied Cognition to Embodied Cognition}

Cognitive psychology emerged in the mid-1950s. George Lakoff, a cognitive linguist and Mark Johnson, a cognitive scientist, co-authored the book, i.e., Philosophy in the Flesh: The Embodied Mind and Its Challenge to Western Thought and they divided the development of cognitive science into the first-generation and the second-generation. The first generation of cognitive science regarded cognition as a rational operation, arguing that the mind is independent of the body and that the cognitive process is similar to the processing process of a computer. Bodymind dualism, individualistic epistemology, and element methodology lay the foundation of the first-generation cognitive science. However, this simplified model of the information processing could not match the flexible cognitive problems and then the connectionist theory came into being. The new theory was based on the reticular formation of brain neurons and the principle of parallel distributed processing. Although more practical, the Connectionism is consistent with the symbolicism in essentially. Unlike the first-generation cognitive science, the second generation is influenced by the phenomenology and emphasizes the integration of mind and body, the situatedness and the embodiment of the cognitive process. Then the concept of embodied cognition was fostered. Therefore, the second-generation cognitive science is also called Embodied Cognitive Science. Since the 1970s, the development of embodied cognition has gradually led to a reflection of the disembodied cognition. It is believed the body and the mind are independent of each other and that the former is only the vehicle carrying the latter, downplaying the perception of the body in the cognitive process. In contrast, the second-generation embodied cognition emphasizes that cognition is closely connected with the body, the environment and the society, i.e., affirms the key role of the body in cognitive activities.

The new orientation of embodied cognition is not a groundless claim but the result of the philosophical reflection as well as the experimental evidence from the psychology and the neuroscience. An American psychologist, i.e., William James and a Danish physiologist, i.e., Carl Lange, coincidentally proposed similar theories of emotion in 1884 and 1885 respectively. The theory claimed that "when the body produces physiological experiences, we feel these changes and this is emotion". The James-Lange theory suggests that stimuli trigger activity in the autonomic nervous system and lead to physiological changes that cause changes in mood, such as crying leading to sadness and running away leading to fear ${ }^{1}$. This theory shows the direct relationship between emotional changes and bodily changes and reveals the important role of body in emotions. The French phenomenologist, Maurice Merleau-Ponty, in his book Phénoménologie de la perception, explicitly put forward a theory of mind on the philosophy of embodiment. He argues that the body is the subject of perception and the cognition exists in every perceptual and behavioral activity of the body, and that the essence of bodily phenomenology lies in replacing the expression of consciousness with the expression of the body. ${ }^{2}$

Jean Piaget established the system of Genetic Epistemology, which affirmed the dependence of cognitive and psychological functions on external activities, the role of physical actions in individual cognitive development, and that the cognitive

\footnotetext{
$\mathrm{a}^{*}$ Corresponding author: e-mail: 61532512@qq.com

be-mail: 769420656@qq.com

ce-mail: 1046253108@qq.com
} 
development was the result of the interaction between the body and the environment. ${ }^{3}$ Over the years, different theories have pointed out the connection and the interaction between the body and the cognition from various perspectives, paving the way for the formation of embodied cognition. In addition, laboratory results have further validated the theory of embodied cognition and confirmed the relationship between the body and the cognition. In 1980, social psychologists, i.e., G. L. Wells and R. E. Petty, conducted an experiment in which they divided the subjects into three groups, i.e., those moving their heads vertically (nodding), those moving their heads horizontally (head shaking), and those not moving their heads and then asked them to rate the headphone set in terms of comfort and sound quality. The statistical results showed that first group (nodding) gave much higher rating than the other two groups while the second group (head shaking) gave much lower rating than the other two groups. ${ }^{4}$ The result demonstrates that the body has an impact on emotional cognition and validates the fundamental hypothesis of embodied cognition. In the 1990s, Rizzolatti and other researchers in the Neuroscience Center of the University of Parma in Italy discovered for the first time that there is a special type of neuron in the brains of monkeys. This type of neuron can be activated when the monkey grabs an object or observes another individual performs in the same way. Therefore, this type of neuron is called Mirror Neuron. Based on the observation, the experimentalists discovered that the mirror neurons also exist in multiple regions of the human brain through techniques such as transcranial magnetic stimulation (TMS) and positron emission tomography (TET). In 2015, Italian neurophysiologist, i.e., Vittorio Gallese and Leonardo Fogassi, put forward the embodied simulation theory based on the discovery of the mirror neurons and provides a scientific basis for the embodied cognition that transcends phenomena by effectively sharing others' gestures, meanings and intentions. ${ }^{5}$ The Metaphors We Live By, by George Lakoff and Mark Johnson, suggests that metaphor is an important way of human cognition, and that embodied cognition helps humans understand concepts. ${ }^{6}$ Human language is also the evidence of embodied cognition.

\section{2 "Human- Object -Environment" From the Perspective of Embodiment}

\subsection{Situatedness/ embeddedness}

The embodied-embedded cognitive paradigm is also called as Heideggerian cognitive science. According to Heidegger, unlike the reflective activity of the brain, daily cognition characterized by situatedness and pre-reflection is much more general. Situatedness is just the essence of such cognition as well as the synonym of the so-called embeddedness. "I" crossed a door without thinking about whether it is big enough to get in; "I" drive around a corner without realizing the existence of the car body; "I" sit down absently in a chair without thinking about its size and whether it can support my weight; "I" use a mouse without thinking about its existence..... Such state of natural interaction is what Heidegger calls "readiness-tohand," an original state in which our bodies use tools masterly and in an appropriate way. Heidegger uses the word "Dasein", which can be regarded as situational being, in place of such terms as subject, ego or the "I think". It is what Merleau-Ponty means by "ambiguity": "ambiguity" derives largely from situatedness: on the one hand, the formation of perception depends on the situation where the object is located rather than the isolated object; on the other hand, people perceive not only the visible nature of an object, but also the invisible part during a perception activity. ${ }^{7}$ Wilson summarized six points for the embodied cognition: (1) "Cognition is situated"; (2) "Cognition is time-pressured"; (3) "We off-load cognitive work onto the environment"; (4) "The environment is part of the cognitive system"; (5) "Cognition is for action"; (6) "Offline cognition is body based"; ${ }^{8}$ Tang Lintao explains "human-object-environment" relationship in this way: Technology "invades" the body and the body becomes a part of mouse, a tool, and the machine. Ergonomics allows people to modify technical systems according to human physiological characteristics. It seems to extend and liberate our heavy physical bodies and overcome the limits of the body. However, it in fact lead to the colonization of the body by technical systems. ${ }^{9}$ While this view suggests more philosophical and techno-ethical reflection, it objectively describes how bodies and artifacts operate in the environment.

\subsection{Mind-Body Complex}

In fact, the second-generation cognitive psychology does not completely abandon the idea in the first-generation that the brain is dominant and that the physical stimuli and the environmental influences need return to the brain for further processing. However, embodied cognition pays more attention to not only the material exchange between the brain and the body but also the interaction between the Mind-Body complex and the environment of the here and now. This view "makes it possible to clarify the relationship between the material exchange activities of body and brain, the Mind-Body complex and the external environment, the complex and past events, and encountered others etc." 10 The boundary between the Mind-Body complex and the objects is blurred. For example, infants have no self-body awareness at first. However, in the interactions with others, an infant can perceive the bodies of the others and his own and then recognize the boundary between himself and the others. It is the result of evolution for someone to be aware of the boundary of the self, such as mammalian territorial awareness. But awareness of the ambiguity of boundaries is currently only attainable by humans. There is no natural boundary between the Mind-Body complex and the environment since some substances and media can be internalized as part of our bodies. For example, without measuring and comparing the width of the alley and the car, one can make an intuitive decision and drive through it. That is so-called "human-car unity". ${ }^{11}$ (pic 1) 


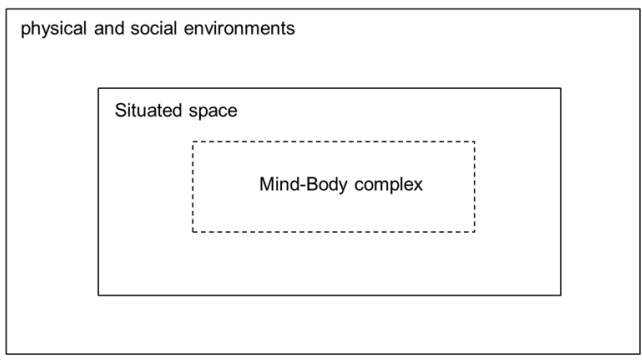

Pic1: Mind-Body complex in environment

\section{The Embodied Nature of Design: Interpretation of Intuitive Design with Affordances Theory}

Affordances of the environment are what it offers the animal, what it provides or furnishes, either for good or ill. The concept of Affordance that lays the basis of ecological psycology, is defined by James Jerome Gibson in his book as the following: affordances of the environment are what it offers the animal, what it provides or furnishes, either for good or ill. "It implies the complementarity of the animal and the environment." ${ }^{12}$ Gibson said. Donald Arthur Norman has repeatedly emphasized the difference between "affordances" and "signifiers". According to Norman, "affordance" refers to the relationship between an object and a human, or more specifically, between the nature of the object and the ability of the subject that determines affordance of objects. Designers such as Masato Sasaki agree that animals have the ability to measure affordances of the environment, and that animals do so all the time unconsciously through perceptual systems. ${ }^{13}$

Intuitive design can be traced back to Jane Fulton Suri of IDEO, who advocates designers guide design activities by observing and documenting people's "thoughtless acts". In her book Thoughtless Act? Observations on Intuitive Design which records a range of examples about thoughtless acts, she said "thoughtless acts are all those intuitive ways we adapt, exploit, and react to things in our environments". She thought that thoughtless acts can "demonstrate the kind of real-world observational approach that can inspire designers and anyone involved in creative endeavors." In addition, IDEO advocates "Bodystorming" method, that is, to activate the body and wake up the brain through role-playing and action recording and then to realize empathy with the users.

A designer, Naoto Fukasawa, tries to apply "unconsciously learned knowledge" to product design. He called memories that the body is not aware of, or that the conscious mind has forgotten, as "active memory". ${ }^{14}$ For example, we do not remember the shape of the metro handrail that we hold on every day but our hands do. If the shape of handrail changes one day, our body will perceive at once. This "active memory" integrated with the body is a collective memory from a shared experience of everyday actions or phenomena, rather than a unique experience of an individual or something that is consciously remembered. Naoto Fukasawa intends to awaken people's "active memories" through design. Naoto Fukasawa believes that good design is about discovering what the body has already discovered but mind has not. (pic2) It can be said that intuitive design is brought by the designer's thorough consideration of physical interactions, sensory experiences and the environment. Design is used to match the mental model of users and thus reduce the cognitive load. The designs of Chiaki Murata, Oki Sato, Kenya Hara, Kazuya Koike, Tokujin Yoshioka and other designers all carry out such an idea, i.e., behaviors lead design. There is no denying that "intuitive design" makes the actions smoother and leads to a more convenient life. Thus the relationship between Human, objects and environment can be more harmonious.

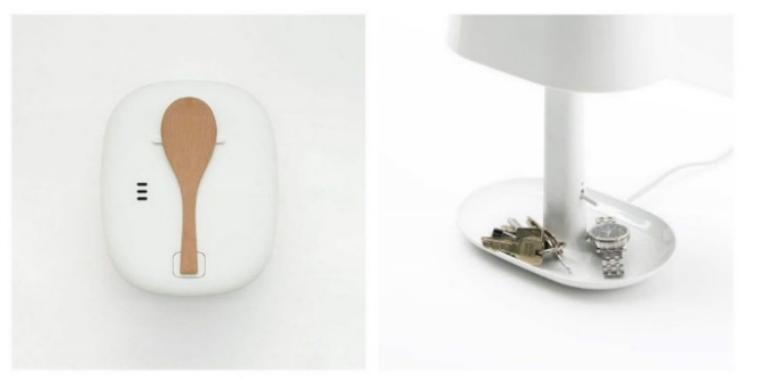

Pic2: Multi-functional lamp and rice cooker designed by Naoto Fukasawa

\section{Design Research and Its Method In the Theory of Embodied Cognition}

The transition of cognitive psychology from disembodied to embodied reflect to the development and change of design research. Around the 1960s, early design researchers, such as Herbert Alexander Simon, introduced the computational theory to develop systematic design problem-solving methods, attempting to establish absolute scientific standards for design processes and tools. This led to design research focusing on design methods from the very beginning, hence the name "design methods movement". In the 1970 s, the research and practice of the scientific design has been questioned and rethought. More people believe that design is a process of finding a "satisfactory solution" rather than an "optimal solution". Even Herbert Alexander Simon proposed the idea of "bounded rationality". Throughout the development of cognitive psychology, the turn from disembodiment to embodiment shares the same time line as the turn to 'rational-finite rationality' in design research.

Disembodied cognition, which treats the human brain as a computer and considers the body as a mere vehicle for the mind with no influence on cognition, is consistent with the purely scientific and rational standpoint of early design research. Embodied cognition, which emphasizes the role of the body and the environment in cognition, partly supports Simon's theory of "Bounded rationality". That is, design is the science of "limited rationality" because human cognition, influenced by complex environments, etc., can have an irrational component by nature. As a result, the methods and the approaches for design research have changed accordingly. 
Today, although the measurement of the brain is still an important and popular tool in design research, the embodied nature of cognition constantly reminds us of the importance of the body and its actions. As the interacting subject with the artificial objects in the environment, it is the cognition formed by the Mind-Body complex that is the psychological basis for the design.

It is optimistic to predict that, with further research of the body, the relationship between mind and body will be revealed and confirmed in design research and that a more complete and comprehensive theory of 'experience' in design research will gradually take shape.

\section{References}

1. William James, "What is an emotion?" Mind. vol.9, no. 34: 188-205. 1884.

2. YE Hao-Sheng, "Principles and Applications of Embodied Cognition," Beijing: The Commercial Press, pp.63-64, April 2017.

3. YE Hao-Sheng, "Embodied cognition: a new approach in cognitive psychology," Advances in Psychological Science, vol. 18, no. 5, pp.705-710, 2010.

4. Gary L. Wells, Richard E. Petty, "The effects of overt head movements on persuasion: Compatibility and incompatibility of responses," Basic and Applied Social Psychology, vol.1, no.3 ed,19-230,1980.

5. Ding Jun, Chen Wei, "The roots of embodied cognition: from mirror neurons to embodied simulation," Journal of Huazhong Normal University (Humanities and Social Sciences), vol. 48, no. 1, pp. 132-136, Jan 2009.

6. George Lakoff, Mark Johnson, "Metaphors We Live By," Hangzhou: Zhejiang University Press, March 2015.

7. Meng Wei, "Embodiment and Cognition: the New Way to Exploration to Human Mind," China Science \& Technology Press pp.57-59,pp.36, April 2020.

8. Wilson M, "Six views of embodied cognition," Psycho- nomic Bulletin \& Review, vol. 9, no. 4 ed, pp.625-636, 2002.

9. Tang Lintao, "Body and consciousness in design," Packaging Engineering, vol. 40, no. 20, Oct 2019.

10. Paul J. Thibault, "Brain, mind and the signifying body: an ecosocial semiotic theory," London: British Library Cataloguing-in-Publication Data, p. 5, 2004.

11. Zhu Lin, "Embodied cognition: cognitive semiotics of the body," West Journal, vol. 3, 2018.

12. James Jerome Gibson, "The Ecological Approach to Visual Perception," Psychology Press, vol. 1, November 2014.

13. Takeshi Goto, Masato Sasaki, Naoto Fukasawa, "The Ecological Approach to Design," Guilin: Guangxi Normal University Press, pp. 27-28, 2016.

14. Takeshi Goto, Masato Sasaki, Naoto Fukasawa, "The Ecological Approach to Design," Guilin: Guangxi Normal University Press, pp. 96-97,2016. 